\title{
The Effectiveness of Anger Instruction in Behavioral- Cognitive Approach on Improvement of Marital Life Quality
}

\author{
${ }^{1}$ Masoumeh Otaghi \\ 2Sattar Kikhavani \\ ${ }^{3 *}$ Reza Valizadeh \\ ${ }^{1}$ Faculty of Nursing \& Midwifery, Ilam University of Medical Sciences, Ilam, Iran \\ 2, 3 Faculty of Medicine, Ilam University of Medical Sciences, Ilam, Iran \\ *Corresponding Author; Email: dr_rezavalizadeh@yahoo.com
}

\section{Doi:10.5901/mjss.2016.v7n4s2p26}

\begin{abstract}
Anger is a natural excitement that we experience it in our life, but when it occurs many times and the approach of expressing it is not appropriate, it would leads to a destroying sense and makes unpleasant consequences for person and others. The aim of this study is to investigate the effect of anger instruction in behavioral- cognitive approach on improvement of marital life quality. The sample of this semi-experimental research was 30 couples among those couples who referred to llam province consultation center in 2015. They were put in two groups of test group (15 couples) and control group (15 couples) randomly. Anger control instruction in behavioral- cognitive approach was set in 8 sessions, 90 minutes and given to test group. The research hypothesis was that anger control instruction in behavioral-cognitive is effective on marital life quality. In order to data analysis one way co-valiance was used. Anger control instruction in behavioral- cognitive approach reduce the marital aggression $(P=0.001)$. This study approves the role and effect of anger control instruction in behavioral cognitive approach on improvement of marital life quality.
\end{abstract}

Keywords: marital aggression, anger control instruction, behavioral cognitive approach

\section{Introduction}

Anger and aggression are worldwide excitements that have seen in all cultures and are one of the popular behavioral problems that results in others' worry and distraction, destroys society's psychological health; It is difficult to present an exact definition of aggression, because in conventional language this term is applied in various ways (Mahmoodabadi Namazi, 1999). Although anger structure is common with aggression and hostility, but these terms are not synonym and just overlap each other. Anger, hostility and aggression are defined as excitement, attitude and behavior, respectively. Anger is defined as a type of emotional state that can be a base for aggression and hostility. Hostility is referred to an aggressive attitude which leads a person to aggressive behaviors, while aggression is defined as visible behavior by intention to make damage (Del Vecchio \& O'leary, 2009). Spielberger believes that anger is an emotional state by various intensities which likes other emotions accompanies with biological and physical changes. External and internal incidents, both can make anger; not only anger leads to negative psychological consequences, but also increases person's vulnerability to disease and results in immune system weakness, pain increase and risk of death due to cardiovascular disease (American Psychological Association, 2003). Fincham believes that anger results in unhealthy behaviors and accompanies with psychosocial characteristics related to vulnerability (such as intense and repetitive conflicts) (Fincham, 1999).

Generally, anger is a quiet useful and normal human emotion; but if it is out of control and be destroying, can results in disruption at job, personal relations and global quality of life (Mahmoodabadi Namazi, 1999). The aim of anger control interventions and treatment is decrease of emotional senses and physiological arousal due to anger, individuals' awareness from anger and instructing effective methods and strategies in order to control it. In fact anger management do not proceed to remove anger, but it proceeds to encourage self recognition, emotional and behavioral supervising which is one of self control ways (Iwaniec, 2006). Cognitive readiness, acquiring skills and applicable instructions are considered as the main variables of anger management program in most of models that were presented for anger management (Shokoohi-Yekta, Behpajooh, Ghobari- Bonab, Zamani, \& Parand, 2008). Occurring conflict and opposition 
between couples is common. Because of couples' interaction nature sometimes they are disagree to each other or their needs don't meet, so couples feel anger, hopeless and dissatisfaction. Marriage leads to problem and conflict cause of many reasons. High rates of divorce in Iran and in the world are the clear indication of couples' life problems. In USA among any two marriages one leads to divorce and statistics show that 80 percent of students in some schools belong to divorced parents and destroyed families (Burns, 1999; Sana'i Zaker, 1999). Some of behavioral interventions are: increasing positive and pleasant behaviors, improving relationships, being able to solve problems, making change in damaging patterns that couples may have, finding some ways to prevent destroying and intense conflicts and attempting to change behavioral patterns which lead to marital problems (Kirk, \& Clark, 1998). A few of studies investigated the combination of behavioral interventions with cognitive reconstruction (Sana'i Zaker, 1999; Bacuom, Sayers, \& Sher, 1990). The results of these studies have shown although cognitive interventions lead to make more cognitive change and behavioral interventions lead to change interactions, but combining behavioral interventions with cognitive reconstruction ways are effective as the same as behavioral therapy (Dattilio, 1993).

Studies show applying techniques of behavior therapy (training problem solving and relationship skills) has effect on preventing divorce and increasing the relationship. This program at individual or group level is effective for those couples that newly marry or some years ago they have married (Elleven, 2002; Simpson, 2001). Bacuom et al have investigated the results of four researches about behavior therapy of marital problems of 148 couples. Reanalysis of treatment results showed that clinical progress of 54.7 percent of couples in contrast to non progress of 5.4 percent of them is significant. At the end of treatment course 35.3 percent of couples have no sign of relationship disruption (Bacuom, Sayers, \& Sher, 1990). Investigating the results after a six month course has shown positive treatment changes was being stable in 60 percent of couples (Besharat, 2000). 42 couples with aggression and Violence problems (low to medium) by random were placed at two treatment groups. One of the groups of couples individually and the second one in group were under treatment and 9 couples were selected as control group. Six months after treatment, repeatation of aggression of couples who has participated in treatment group was significantly lower than control group, their marital satisfaction has increased, and male aggression and acceptance of aggression from female side was significantly decreased in compare to control group and group of couples who were under treatment individually (Stiths, Rosen, McCollum, \& Thomsen, 2004).

Lesure in his study has shown the usefulness of cognitive, behavioral and emotional principals in increasing mental health (Lesure, 2002). Banijamali et al in a study titled finding the origins of causes of families disruption in relation to girls' and boys' social- psychological characteristics before marriage shown that fiscal pressure has a negative impact on maritals' relationships, and are one of the factors of family turbulence. Also investigations show that parents and individuals around couples in unsuccessful families have a key role in not being success and separation (Banijamali, Nafisi, \& Yazdi, 2005). Markman in a research have embarked to investigate the effect of behavioral therapy strategies (problem solving instruction, to instruct relationship and cognitive reconstruct) on raising divorce and frustration of couples (Simpson, 2001; Markman, 1993). Linkh \& Sonnek in their study has investigated the effect of anger control instruction by behavioral- cognitive method. In this research 91 persons with the problem of inability to control their anger were replaced at two groups randomly, behavioral- cognitive treatment group and control group. Results showed the progress of subjects in ganger controlling at test group was significantly more than control group (Linkh \& Sonnek, 2003). Lange et al in their study have investigated the effectiveness of anger control for helpless couples. In this research some assignments were gave to 28 couples at three sessions with the end of increasing abstinence and expressing thoughts and emotions in a congenial way. Results showed the couples have significantly improved in control their anger (Lange, Barend, \& Ende, 1998). Also a research investigated the effect of communication skills training with cognitive-behavioral approach on marital adjustment rate and it found that cognitive therapy will increase couples' satisfaction. Aghamohammadian in his study has found that cognitive consultation in group has a positive effect on increase of teenagers' adjustment (HajiAbulzadeh, 2003; Aghamohammadian, 1999).

Studies show using interventions which respect to behavioral- cognitive and emotional approaches, has effective to prevent divorce and to increase relationship. These programs are effective for all of those who newly marry or those who have married some years ago (Elleven, 2002; Simpson, 2001; Dattilio, 2007). The present study has done by the end of investigating the effectiveness of anger control instruction in behavioral- cognitive approach on improving marital life quality of couples in llam.

\section{Material and Methods}

The method of this research was semi- experimental that was conducted at a protest- pretest design with control group. The sample of this research included couples who were settled at llam that have referred to consultation center of Imam 
Hospital from September to 10 November 2014. This sample was selected by accessible sampling, so that those couples who have referred to consultation center because of problems and conflicts' marital, also those couples who have enrolled in group through announcement, after interview and filling the Enrich questionnaire of marital satisfaction 30 couples were selected. Then members were placed in test and control groups by random. 15 coupled in test group and 15 couples in control group were placed. Dependent variable in this study was marital aggression that was investigated by Enrich satisfaction questionnaire. Research instrument was interview and Enrich satisfaction questionnaire. The independent variable was anger control through cognitive- behavioral approaches that was set at 8 sessions, 90 minutes and was instructed to test group at consultation center of Imam Hospital. After interview and filling the Enrich satisfaction questionnaire 30 couples were selected. Then members were placed in test and control groups randomly. The content of sessions was selected and conducted- according to research literature and CBT approach. The rubric of treatment sessions was given at table 1 . In order to data analysis covariance data analysis test (ANCOVA) was used.

In this research, the researcher has considered ethical requirements and ethics in this study, it was assured to sample members that filling and presenting questionnaire has no social, economical and legal results and presented data was considered secret and they are used just for statistics. Since individuals have presented their real opinions, they were asked to don't state their name and personal information. At the end the results were extracted, written and reported.

Enrich marital satisfaction questionnaire: This questionnaire was prepared with 15 items by Olson (1997) for the first time, then the form of 47 item was constructed, that in this study this form was used. The recent form has variables of relational, financial management, leisure times, sexual relations, parents' duties, friends and family, making religion directions, personality issues and solving conflict. Olson and Olson (1997) have reported the total value of this form by using of Alpha Coefficient Method (0.92). Soleimanian was calculated and reported the internal integrity for the long form as 0.93 and for short form as 0.95 , for the first time in Iran.

In the present research the Cronbach's alpha for this questionnaire was 0.92 , for marital relationship variables was (0.91), financial management was (0.59), leisure times was (0.55), sexual relations was (0.78), parent duties was (0.88), friends and family was (0.69), making religion directions was (0.60), personality issues was (0.87) and solving conflict was (0.67) obtained. Also in the present study Cronbach's alpha of overall questionnaire was obtained 0.96 which shown the high internal uniformity of test, Enrich questionnaire correlation coefficient is 0.32 to 0.41 that shows construct validity.

\section{Findings}

In this study, 30 couples who have a high score of marital aggression were selected and studied. Couples were placed at two control and test groups. The mean of pretest of test group was 111.15 and the mean of pretest of control group was 114.60 that were not significant statistically. In the post test, the mean of test group was 85.20 that in compare to mean of post test of control group (120.70) were decreased significantly. The descriptive results were presented at table 2.

In order to assess the effectiveness of group instructing behavioral- cognitive control of anger on marital aggression one way covariance analysis was used. the obtained results shown that by controlling pre test between unrest couples of test groups and control respect to total score of aggression of espouse there is a significant difference $(\mathrm{F}=236.550, \mathrm{P}=0.0001)$. In other word group instructing cognitive behavioral according to mean of test group aggression (85.20) in relation to mean of control group aggression (120.70), leads to significant decrease of aggressiveness at test group. The amount of impact or difference is equal to 0.86 ; it means that 0.86 of individual difference in spousal aggression scores relates to the effect of behavioral cognitive instruction. So instruction of behavioral cognitive group leads to decrease the marital aggression among unrest couples in llam city (Table 2). 
Table1. The total structure of anger management instruction sessions

\begin{tabular}{|c|c|c|}
\hline $\begin{array}{l}\text { Number } \\
\text { of session }\end{array}$ & Title & Content \\
\hline 1 & $\begin{array}{l}\text { Introduction, anger definitions } \\
\text { and its consequences }\end{array}$ & $\begin{array}{l}\text { Introducing group members, introducing program and presenting total aim of anger management } \\
\text { instruction and the importance of attend to it, group rules and general expectations from program, defining } \\
\text { anger and its synonyms. Explaining anger concept and relevant concept and their separation discussion } \\
\text { and recognition undesirable consequences from uncontrolled anger }\end{array}$ \\
\hline 2 & $\begin{array}{l}\text { Anger incentive and common } \\
\text { response of personal patterns } \\
\text { from experiencing anger and } \\
\text { behavior }\end{array}$ & $\begin{array}{l}\text { Explaining creativity to anger or factors which making anger motivation, concepts with suitable sample } \\
\text { and confronting requirements. Investigating potential advantages and disadvantages of anger in a simple } \\
\text { way. Investigating and recognizing physical signs, thoughts and behaviors in experiencing anger } \\
\text { excitement. Reporting the anger occurrence by group members in order to study the extent of members' } \\
\text { learning and understanding the self anger pattern of this group. In this respect each member of a group } \\
\text { explains the incidents related to self anger and self experience. Personal anger patterns shows reporting } \\
\text { his/her behavior when he/she is angry, and describing all changes of body at the moment of being angry. }\end{array}$ \\
\hline 3 & $\begin{array}{l}\begin{array}{l}\text { To supervise on critical signs of } \\
\text { anger, calmness and decrease } \\
\text { the tension }\end{array} \\
\end{array}$ & $\begin{array}{l}\text { In this session, two state of calmness and tension of body has being compared and their differences were } \\
\text { placed simply. Exercises related to calmness strategy were conducted in details. }\end{array}$ \\
\hline 4 & $\begin{array}{l}\text { Making a phenomenon vision, } \\
\text { understanding motivation and } \\
\text { anger experience }\end{array}$ & $\begin{array}{l}\text { The concepts of understanding phenomenon cognition motivation were placed simple. The role of } \\
\text { personal understanding of motivation for intensify anger were explained and was referred to some suitable } \\
\text { samples. }\end{array}$ \\
\hline 5 & $\begin{array}{l}\text { The role of negative thoughts in } \\
\text { experiencing anger, changing } \\
\text { negative thoughts and } \\
\text { controlling anger }\end{array}$ & $\begin{array}{l}\text { The negative role of self reporting and unuseful thoughts in experiencing anger and behavior aroused } \\
\text { from it was explained. The concepts of thoughts, beliefs and expectations stimulation by some proper } \\
\text { explanations were explained. A list of thoughts, useful and constructive beliefs and expectations based on } \\
\text { anger management was presented. Mutual effects from negative thought and anger experience with a } \\
\text { proper sample was explained. A list of positive thoughts as a proper alternative for negative thoughts and } \\
\text { with group members' collaboration. By role playing and making a scene to confront with negative } \\
\text { thoughts. }\end{array}$ \\
\hline 6 & $\begin{array}{l}\text { Self comment to control anger, } \\
\text { courage instruction and } \\
\text { relationship skills }\end{array}$ & $\begin{array}{l}\text { The concepts of self order will present while referring to some definitions of related sample. Presenting } \\
\text { proper actions in order to use in different situations. In addition instruction to distract self attention away } \\
\text { from provocation and requirements to challenging thoughts and self decision making was gave. The } \\
\text { concept of courage was defined, and the importance of using courageous behavior. Then, courage by } \\
\text { comparing reaction and trespass and the features of these three behaviors was presented. The role of } \\
\text { effective relational skills, especially courage in managing control was explained. Representing courage } \\
\text { role playing of each member. }\end{array}$ \\
\hline 7 & $\begin{array}{l}\text { The strategy of problem solving } \\
\text { instruction }\end{array}$ & $\begin{array}{l}\text { The instruction to solve a problem will strategic and explaining its constituents (problem, solution, choice } \\
\text { and results), the importance and necessity of using strategy of problem solving in anger management } \\
\text { context was presented and by some related sample were explained. The strategy to solve problem or } \\
\text { listening to real actions or imaginary actions in order to deepen learning were presented. }\end{array}$ \\
\hline 8 & $\begin{array}{l}\text { Making safety in confront with } \\
\text { stresses of anger control } \\
\text { instruction }\end{array}$ & $\begin{array}{l}\text { Use of making safety instruction in confront of anger control management stress is a method that simply } \\
\text { conducted. How to use imaginary confrontation and response inhibition were shown by referring its steps. } \\
\text { The hierarchy of potential stimulation is provided in cooperation with the members of the group }\end{array}$ \\
\hline
\end{tabular}

Table2. Mean and standard deviation of aggression score of test and control group in pre and post test

\begin{tabular}{lccccc}
\hline & Stage & Group & Number & Mean & Standard deviation \\
\hline & Pre & Test & 15 & 111.15 & 8.96 \\
The total score of aggression & test & control & 15 & 114.60 & 9.57 \\
& Post & Test & 15 & 85.20 & 7.45 \\
& test & control & 15 & 120.70 & 9.57 \\
\hline
\end{tabular}

Table3. The results of one- way ANCOVA to investigate the significance of the difference between test and control groups

\begin{tabular}{cccccc}
\hline & Sum of squares (SS) & $\begin{array}{c}\text { Mean } \\
\text { squares (MS) }\end{array}$ & $\begin{array}{c}\text { Degree of } \\
\text { Freedom (DF) }\end{array}$ & F & $\begin{array}{c}\text { Level of } \\
\text { significance }\end{array}$ \\
\hline Aggression & 10825.059 & 1 & 10825.059 & 236.550 & 0.001 \\
Pretest & 1104.195 & 1 & 1104.195 & 24.129 & 0.001 \\
Error & 1693.205 & 37 & 45.762 & & \\
\hline
\end{tabular}

\section{Discussion}

The results of this study showed behavioral- cognitive consultation in a group has effected on decreasing of marital 
aggression of test group in comparison to control group. The positive effect of behavioral- cognitive method in decreasing the marital conflicts is in accordance with research results (Markman, 1993; HajiAbulzadeh, 2003). It can be said that some studies have behavioral nature, require the attitude to simplify and attain changes in couples' behavioral patterns, and cognitive therapists have placed their approach on couples' thinks and beliefs. For cognitive therapist who works with couples, reconstructing perverted beliefs has a critical effect on changing maladaptive behaviors (Goldenberg \& Goldenberg, 2003).

The results of this study represent that behavioral- cognitive method is effective on decreasing emotional reactions (aggressiveness and depression). These findings are in accordance with studies in the context of useful interventions to prevent and treat depression of couples and to control anger and abstinence (Stiths, Rosen, McCollum, \& Thomsen, 2004; Markman, 1993; Linkh \& Sonnek, 2003; Lange, Barend, \& Ende, 1998). Sometimes fundamental motivations of anger and depression originated from incorrect beliefs and perverted recognitions. In controlling anger and depression, cognition and awareness cause that anger to be stated in a constructive form and the signs of depression will decrease. The factors that make anger and depression be recognized and controlled and the proper answers to wife or husband to be learnt (Lesure, 2002; Banijamali, Nafisi, \& Yazdi, 2005; Markman, 1993; Linkh \& Sonnek, 2003; Lange, Barend, \& Ende, 1998; HajiAbulzadeh, 2003; Aghamohammadian, 1999; Dattilio, 2007; Goldenberg \& Goldenberg, 2003; Klenick, 1998).

\section{Conclusion}

Using cognitive- behavioral interventions it can be pay attention to control and to solve couples' conflicts on different matters. According to the effectiveness of cognitive- behavior method on the decrease of conflicts, consultants and psychologists of psycho therapy service center and consultation can use these two approaches in order to decrease conflicts and marital aggressions.

\section{References}

Aghamohammadian, HR. (1999). The effect of cognitive therapy approach on increased to adolescent adjustment. Doctoral thesis. TARBIAT MODARES University Iran.

American Psychological Association .(2003). Controlling Anger before it controls you. http://www.apa.org/ pubinfo/anger.html.

Bacuom, DH., \& Sayers, SL., Sher TG (1990) Supplementing behavior marital therapy with cognitive restructuring and emotional expressiveness training. Journal of Consulting and Clinical psychology, 58 (5): 636-645.

Banijamali, Sh, Nafisi, Gh, \& Yazdi, SM. (2005). The root causes of the disintegration of the families in relation to psychosocial characteristics of girls and boys before marriage. Journal of science education and psychology, 11: 143-170.

Besharat, MA. (2000). Models for couple therapy. Journal of New Psychotherapies, 5 (17,18):23-31.

Burns, D. (1999). Cognitive therapy: from bad mood to good. Translated by Gharachedaghi, M. Tehran: ARIANKAR.

Dattilio, FM. (1993). Cognitive techniques with couples and families. The Family Journal, (1): 51-65.

Dattilio, FM. (2007). The role of cognitive behavioral intervention in couple and family therapy. Journal of Marital and Family Therapy, 31(1):7-13.

Del Vecchio, T., \& O'leary, D. (2009). Effectiveness of anger: treatment for specific anger problems: A Meta analytic review. Journal of American Academy Psychiatry Law, 37(4): 473-488.

Elleven, KR. (2002). Relationship success. Retrieved form: http://www.marrige-education.net/nre-htm.

Fincham, FD. (1999). Conflict in marriage: Implication for working couples. Annual Review of Psychology, 50: 47-77.

Goldenberg, A \& Goldenberg, H. (2003). Family therapy. Translated by Shah Baravati, HRH., \& Naqshbandi, S. Tehran: Mental publication.

HajiAbulzadeh, N. (2003). The effect of communication skills training with cognitive-behavioral approach on marital adjustment rate. Master thesis. University of Al-ZAHRA, Iran.

Kirk, H., \& Clark, SK. (1998). Cognitive Behavioral Therapy. Translated by Ghasemzadeh, H. Tehran: ARJOMAND.

Klenick, CL. (1998). Coping with life challenges. http://www.waveland.com/browse.php?t=329.

Lange, A, Barend E, Ende, J. (1998). Self control in distressed couples: A pilot study. Journal of Family Therapy, 20(4): 367-382.

Lesure, G. (2002). An application of cognitive behavior principles In the reduction of aggression among abused African American Adolescents. Journal of Inter Personal Violence, 17: 394-402.

Linkh, D., \& Sonnek, SM. (2003). An application of cognitive behavioral anger management training In a military occupational setting. Military Medicine Journal.168(6):475-8.

Iwaniec, D. (2006). The emotionally abused and neglected child. 2nd ed. United Kingdom: Johnwiley \& Sons, Ltd.

Mahmoodabadi Namazi, D. (1999). Effectiveness of training principles and techniques of behavior change to parents of 1-8 years old children for modulating aggression. Master's thesis, ALLAMEH TABATABAEI University.

Markman, H. (1993). Preventing marital distress through communication and conflict management training: a 4- and 5-year follow-up. 
Journal of Counsulting Clinical Psychology, 61(1):70-77.

Sana'i Zaker, B. (1999). The role of main family in children's marriage. Quarterly consulting Research and Development, News and counseling Research, 1(1, 2): 21-46.

Shokoohi-Yekta, M., Behpajooh, A., Ghobari- Bonab, B., Zamani, N., \& Parand, A. (2008). The Efficacy of Anger Management Skills Training on Anger Control of Mothers of Mentally Retarded and Slow Learner Children. J Exceptional Children, 8(4): 358-69.

Simpson, K. (2001). Description of PAIRS programs. file:pairs.html.

Stiths, SM. Rosen, KH., McCollum, EE., \& Thomsen, CJ. (2004). Treating intimate partner violence with in intact couple relationship: Outcomes of multi-couples versus individual couple therapy. Journal of Marital and Family Therapy, 30 (3): 305- 318. 